\title{
O exercício da Advocacia: Estudo comparativo Portugal e Brasil
}

The practice of advocacy: a comparative study between Portugal and Brazil

\section{Sancha de Carvalho e Campanella}

Centro de Investigação ISAL, Portugal sancha.campanella-267m@advogados.oa.pt Allen dos Santos Pinto da Silva

Centro de Investigação ISAL, Portugal allen.silva@gmail.com Jorge Alexandre Rodrigues da Costa

Centro de Investigação ISAL, Portugal jorge.costa@outlook.com 


\section{Resumo}

Este estudo analisa, comparativamente, a caraterização dos contextos atuais da vida advocacia no Brasil e em Portugal, aferindo o crescimento dos cursos de Direito e Universidades, o número de advogados existentes. Desta forma, pretende-se conhecer a realidade atual da advocacia lusobrasileira. 0 estudo justifica-se pelo passado histórico comum aos dois paises, predominado pela forte influência portuguesa na formação cultural e legislativa brasileira, dado o seu passado de Vice-Reinado de Portugal. 0 estudo assume, ainda, particular importância, atendendo ao Tratado de Amizade, Cooperação e Consulta entre a República Portuguesa e a República Federativa do Brasil, assinado em Porto Seguro em 22 de abril de 2000, (Resolução da Assembleia da República $n^{0} 83 / 2000$ de 14 de dezembro, 2000). 0 referido tratado estabelece o livre acesso às profissões entre ambos os países, desde que exista reciprocidade e que cumpram os requisitos exigidos para os nacionais. Por meio das informações e dados colhidos, verifica-se que ambos os países têm mecanismos legislativos e normativos de acesso à profissão de advogado, e fortemente reguladores do estatuto garantido pelas ordens profissionais de inscrição obrigatória, respetivamente $\mathrm{AO}$ e $\mathrm{OAB}$. Constatou-se, por fim, uma forte expansão do mercado jurídico em ambos os paises.

Palavras-chave: Advocacia, Brasil, Direito, Portugal.

\section{Abstract}

This study comparatively analyzes the characterization of the current contexts of law practice in Brazil and Portugal, assessing the growth of Law and University courses, the number of existing lawyers. In this way, it is intended to know the current reality of Portuguese-Brazilian law. The study is justified by the historical past common to both countries, predominated by the strong Portuguese influence in the Brazilian cultural and legislative formation, given its past as the Viceroyalty of Portugal. The study is also of particular importance, given the Treaty of Friendship, Cooperation and Consultation between the Portuguese Republic and the Federative Republic of Brazil, signed in Porto Seguro on April 22, 2000, (Resolution of the Assembly of the Republic $n^{0}$ $83 / 2000$ December 14, 2000). The aforementioned treaty establishes free access to professions between both countries, provided that there is reciprocity and that they fulfill the requirements required for nationals. Through the information and data collected, it appears that both countries have legislative and normative mechanisms for access to the legal profession, and strongly regulate the status guaranteed by professional mandatory registration orders, respectively $\mathrm{AO}$ and OAB. Finally, there was a strong expansion of the legal market in both countries.

Keywords: Advocacy, Brazil, Law, Portugal. 
A palavra Advogado deriva da expressão em latim ad vocatus, que significa o que foi chamado para intervir em nome de terceiro. Por outras palavras, a pessoa responsável por litigar ou defender os interesses de outrem em juízo ou fora dele.

À Advocacia, chamou Voltaire (1694-1778), "a mais bela das profissões humanas" "Le plus bel état du monde" (Neto, 1946).

Por isso, o mandato do advogado é, como afirma o mestre Couture (1987), uma atividade única, prestigiada, nobre e honrosa. Em temos práticos, advogar significa, essencialmente, defender, representar em juízo e fora dele, patrocinar, proteger, orientar, exercer a advocacia. Logo, ser Advogado significa exercer um mandato associado a poder económico e politico, a conhecimento e acesso reservado a determinados fóruns do poder (Poiares, 2018).

Neste âmbito, incumbe a qualquer Estado moderno, garantir os direitos e liberdades fundamentais dos cidadãos; e, em consequência destes direito e liberdades fundamentais, os cidadãos têm 0 direito à informação, à consulta jurídica, ao patrocínio judiciário e a fazer-se acompanhar por um advogado perante qualquer autoridade. Importa salientar que, todos estes direitos se encontram retratados em ambas as constituições, tanto do Brasil, como em Portugal.

Os advogados gozam de estatuto especial e de imunidades necessárias ao exercício do mandato, pelo que ambas as legislações Portuguesa e Brasileira - regulam o patrocínio forense como elemento essencial à administração da justiça. Desta forma, reconhece-se, ainda, aos advogados um lugar central na administração da justiça.
Em Portugal e no Brasil, a profissão é regulada por ordens profissionais, respetivamente a $O A$ e a OAB. 0 atual Estatuto da Ordem dos Advogados (EOA) portugueses foi aprovado pela Lei $n^{0} 145 / 2005$, de 26 de Janeiro. Já 0 Estatuto da Ordem dos Advogados brasileiros (EOAB) foi aprovado pela Lei n. 8.906, de 04 de julho de 1994.

Quer num país, quer noutro, as Ordens dos Advogados constituíram-se como associação publica representativa dos Advogados, e gozam de independência relativamente aos demais órgãos do Estado.

Ambos os Estatutos da Ordem dos Advogados reforçam a ideia central de que "o advogado é indispensável à administração da justiça" (artigo $88^{\circ}, n^{0} 1$ do EOA e artigo $2^{\circ}$ da EOAB), 0 que determina que sem advocacia não há administração da justiça, nem realização plena do Estado de Direito.

Em regra geral, a prática dos atos próprios da advocacia estão reservados aos licenciados em direito com inscrição em vigor na Ordem dos Advogados (artigo $61^{\circ}, n^{0} 1$ do EOA). Contudo, o EOAB vai ainda mais longe ao determinar que que são nulos os atos privativos de advogado praticados por pessoa não inscrita na $O A B$, sem prejuízo das sanções civis, penais e administrativas (artigo $4^{\circ}$ do EOAB).

Ambos os ordenamentos jurídicos determinam que aos advogados é devido, aquando do exercício da sua profissão, tratamento compatível com a dignidade da advocacia, seja por magistrados, agentes da autoridade ou funcionários públicos.

0 advogado exerce a profissão com liberdade (artigo $7^{\circ}$ do EOAB), tendo plena autonomia técnica nesse exercício, o qual faz de forma isenta, independente e responsável (artigos $81^{\circ}, n^{0} 1$ do EOA). 
Nos termos do Tratado de Amizade, Cooperação e Consulta entre a República Portuguesa e a República Federativa do Brasil, assinado em Porto Seguro em 22 de abril de 2000 (Resolução da Assembleia da República n 83/2000, publicado no Diário da República I SÉRIE-A, n 287 de14 de dezembro de 2000) reconhece-se a história comum dos dois países para estabelecer princípios e objetivos para um desenvolvimento de relações entres profissionais de ambos os lados do Atlântico, os quais se encontram decalcados no artigo $1^{\circ}$ do Tratado. Este Tratado comemorou os seus 20 anos de existência e tem sido um marco fundamental nas relações entre Portugal e 0 Brasil.

Neste âmbito, e ao abrigo do referido tratado (artigo $39^{\circ}$ ) os graus e títulos académicos de ensino superior concedidos por estabelecimentos para tal habilitados por qualquer um dos países em favor dos nacionais serão reconhecidos no outro país, desde que certificados por documento devidamente apostilhada, permitido às universidades $\mathrm{e}$ demais instituições de ensino superior em
Portugal e no Brasil celebrar convénios tendentes a assegurar 0 reconhecimento automático dos graus e títulos académicos, assimilando os diferentes programas curriculares ministrados.

0 mesmo Tratado de Amizade, Cooperação e Consulta entre a República Portuguesa e a República Federativa do Brasil, permite, ainda, que o cesso á profissões e seu exercício possam ser efetuados em ambos os países, em condições idênticas às exigidas aos nacionais de cada um. É, assim, estabelecido um princípio de reciprocidade entre ambos os países para o acesso e exercício da profissão, princípio este que é reiterado por ambos os Estatutos Profissionais da Ordens dos Advogados de ambos os países. É neste contexto de amizade e cooperação entre os dois países e da celebração há vinte anos do Tratado de Amizade, Cooperação e Consulta entre a República Portuguesa e a República Federativa do Brasil, que surge o presente texto, com vista a aferir os resultados práticos

\section{Metodologia}

0 presente estudo tem como objetivo proporcionar maior familiaridade com os problemas de acesso e exercício da profissão de advogado em duas nações distintas, mas com fortes laços culturais e interesses no desenvolvimento de soluções no quadro alargado da lusofonia, materializada na CPLP. Trata-se de um estudo de caráter qualitativo, exploratório e descritivo(Gil, 2017; Prodanov \& Freitas, 2013). De acordo com (Gil, 2017; Prodanov \& Freitas, 2013) é a pesquisa recomendada em casos de estudo deste tipo, dado que se apresenta como flexível e na maioria dos casos assume a forma de pesquisa bibliográfica ou estudo de caso. A pesquisa bibliográfica caracteriza-se por analisar e discutir informações já publicadas. 0 objetivo é colocar os investigadores em contacto direto com todo o material já escrito sobre 0 assunto da pesquisa.

Destarte, o presente estudo parte da descrição para uma comparação entre a realidade do mercado jurídico do Brasil e de Portugal, com recurso a métodos estáticos.

Gil (2017) afirma que o método comparativo procede pela investigação de (...) fenómenos ou fatos, com vistas a ressaltar as diferenças e as semelhanças entre eles. "Sua ampla utilização nas ciências sociais deve-se ao fato 
de possibilitar o estudo comparativo de grandes grupamentos sociais, separados pelo espaço e pelo tempo.".
Recorreu-se a fontes secundárias de dados, de forma a interpretar fenómenos e atribuir significados. A fundamentação foi elaborada com 0 estudo de diversos documentos científicos publicados.

\section{A Advocacia nas ordens nacionais}

Para ser advogado em Portugal é necessário ser detentor de uma Licenciatura em Direito, por universidade Portuguesa e inscrição na Ordem dos Advogados.

A Ordem dos Advogados Portuguesa, criada pelo Decreto n. 11715 , de 12 de Junho de 1926, e teve a sua origem na Associação dos Advogados de Lisboa, cujos Estatutos foram aprovados em 1838.

0 Estatuto da Ordem dos Advogados regulamenta os mais importantes aspetos funcionamento da Instituição representativa dos Licenciados em Direito que exercem a Advocacia e estabelece o quadro deontológico do exercício da atividade.

De acordo com Collins (1989), as associações profissionais realizam um "trabalho político" de criação de identidades profissionais, pela via de produção de uma cultura própria a cada profissão, que a distinga das outras profissões, e pela via da normatização profissional. Autonomia ante as outras profissões e controle interno são os objetivos maiores, e o que se espera, das associações profissionais. As profissões são grupos de status. As profissões precisam agir coletivamente, através das associações, para manter a imagem de profissão ideal diante da sociedade.

A inscrição na Ordem como advogado e o exercício da advocacia depende de um tirocínio (Estágio) sob orientação da $\mathrm{OA}$, com a duração de dezoito meses, destinado a habilitar e

certificar que o advogado obteve formação técnico-profissional e deontológica ao cumprimento dos requisitos impostos pelo Estatuto da Ordem dos Advogados. 0 estágio é fortemente regulado pela $\mathrm{Oa}$, que possui um Regulamento de estágio (Regulamento n. ${ }^{0}$ 913A/2015, aprovado em Assembleia Geral da Ordem dos Advogados de 21 de dezembro de 2015), onde se definem as áreas obrigatórias de atuação do advogado estagiários, a formação a receber e os exames a realizar.

Após a realização do tirocínio, o candidato tem que realizar um exame escrito e uma entrevista oral obrigatória de carácter eliminatório.

De acordo com Fundação Getúlio Vargas (2020) o exame tem por objetivo fundamental: proteção da sociedade e do cidadão, sendo preciso garantir que os profissionais responsáveis por resguardar direitos fundamentais como a liberdade, a honra e 0 patrimônio tenham formação mínima adequada.

0 exercício da profissão é fortemente regulado, existindo legislação que define os atos próprios dos advogados e dos solicitadores e que inclusivamente tipifica como crime de procuradoria ilícita estes atos quando praticados por não advogados ou solicitadores (Lei 49/2004 de 24 de Agosto).

De acordo com este diploma legal são atos próprios do advogado ou solicitador:

a) 0 exercício do mandato forense; 
b) A consulta jurídica.

c) A elaboração de contratos e a prática dos atos preparatórios tendentes à constituição, alteração ou extinção de negócios jurídicos, designadamente os praticados junto de conservatórias e cartórios notariais;

d) A negociação tendente à cobrança de créditos;

e) 0 exercício do mandato no âmbito de reclamação ou impugnação de atos administrativos ou tributários.

São atos próprios dos advogados os atos que forem exercidos no interesse de terceiros e no âmbito de atividade profissional, sem prejuízo das competências próprias atribuídas às demais profissões ou atividades cujo acesso ou exercício é regulado por lei, e ainda todos aqueles que resultem do exercício do direito dos cidadãos a fazer-se acompanhar por advogado perante qualquer autoridade.

No tocante ao Brasil, e influenciados pela criação da $\mathrm{OA}$, em 1843, foi criado por Dom Pedro I o Instituto dos Advogados Brasileiros, mas somente em 1930 no governo provisório de Getúlio Vargas é que foi criada a Ordem dos Advogados do Brasil.

Igualmente no Brasil, para se exercer a advocacia, é necessário estar inscrito na $O A B$, inscrição esta que é obtida mediante aprovação no Exame de Ordem, conforme os seus Estatutos. Para inscrição na ordem é necessário ser titular do título de graduação como bacharel em Direito. Desde 1994, que o exame da OAB é obrigatório e desde 2007 é unificado, ou seja, é igual em todo o país, sendo um critério de controle da qualidade das IES.

\section{Mercado Jurídico Brasileiro em} Números.

Muito se fala na saturação do mercado de trabalho jurídico no Brasil. |No entanto, se fizermos um balanço com base nos últimos números disponibilizados pelo Conselho Nacional de Justiça (CNJ), Ministério de Educação e Ciência (MEC), OAB e Instituto Brasileiro de Geografia e Estatística (IBGE) pode-se inferir sobre os dados desse mercado, tão grande e impressionante quanto o próprio país de dimensões continentais.

Pretende-se compreender 0 mercado brasileiro, com fundamentação em dados estatísticos. Assim, numa perspetiva evolutiva, apresenta-se o número de Faculdades de Direito no Brasil.

Atualmente, existem 1.217.918 advogados ativos, sendo 608.661 mulheres e 609.257 homens.

\section{Mercado Jurídico Português em} números

Em Portugal o número de advogados tem crescido exponencialmente, tendo passado de 1964, em 1960, para 33298 no ano 2019 (Tabela 1).

Tabela 1 - Advogados Inscritos na Ordem doa advogados

\begin{tabular}{cccc}
\hline \multirow{2}{*}{ Anos } & & \multicolumn{2}{c}{ Sexo } \\
\cline { 2 - 4 } & Total & Masculino & Feminino \\
\hline $\mathbf{1 9 6 0}$ & 1964 & $\mathrm{x}$ & $\mathrm{x}$ \\
\hline $\mathbf{1 9 7 8}$ & 3818 & $\mathrm{x}$ & $\mathrm{x}$ \\
\hline $\mathbf{1 9 8 0}$ & 5134 & 8477 & $\mathrm{x}$ \\
\hline $\mathbf{1 9 9 0}$ & 11319 & 10111 & 842 \\
\hline $\mathbf{2 0 0 0}$ & 18629 & 12241 & 12166 \\
\hline $\mathbf{2 0 0 5}$ & 24407 & & \\
\hline
\end{tabular}




\begin{tabular}{llll}
\hline $\mathbf{2 0 1 0}$ & 27550 & 13301 & 14249 \\
\hline $\mathbf{2 0 1 1}$ & 27869 & 13377 & 14492 \\
\hline $\mathbf{2 0 1 2}$ & 28182 & 13352 & 14830 \\
\hline $\mathbf{2 0 1 3}$ & 28765 & 13499 & 15266 \\
\hline $\mathbf{2 0 1 4}$ & 29337 & 13690 & 15647 \\
\hline $\mathbf{2 0 1 5}$ & 29699 & 13724 & 15975 \\
\hline $\mathbf{2 0 1 6}$ & 30475 & 13920 & 16555 \\
\hline $\mathbf{2 0 1 7}$ & 31326 & 14195 & 17131 \\
\hline $\mathbf{2 0 1 8}$ & 32368 & 14617 & 17751 \\
\hline
\end{tabular}

Fonte: Direção Geral da Política Justiça (DGPJ)/Ministério da Justiça (MJ) - PORDATA (2020)

Com o aumento dos advogados, o status e 0 poder simbólico atribuído à profissão, como standart da justiça, diminuíram à medida que 0 número de profissionais foi aumentando, como se existisse numa relação de oferta/procura e foi sendo entendido que a qualidade dos serviços prestado aos cidadãos diminuía com este aumento. 0 advogado que tinha uma imagem social associada a uma classe reservada e única com poder económico e até político, a qual foi-se perdendo com a massificação da profissão.

\section{Ensino do Direito no Brasil}

A Lei de Diretrizes e Bases da Educação Nacional (LDB), aprovada em 20 de dezembro de 1996 (Lei $n^{0}$ 9.394/96) retirou as barreiras institucionais e legais para a implantação e estruturação das Instituições de Ensino Superior no Brasil, o que causou um expressivo crescimento do número de IES. De acordo com Fundação Getulio Vargas (2020), o número de instituições de ensino jurídico no país saltou de 235 em 1995, para mais de 1.500, atualmente.

De acordo com dados do Ministério da Educação (2020), em 2019, existiam 2608 Instituições de Ensino Superior (IES), sendo apenas 302 instituições publicas contra 2306 privadas, demonstrando a hegemonia destas (Tabela 2).

Tabela 2 - Instituições de Ensino Superior no Brasil

\begin{tabular}{|c|c|c|c|c|c|c|c|c|c|}
\hline \multirow{3}{*}{ Ano } & \multicolumn{9}{|c|}{ Instituições } \\
\hline & \multirow{2}{*}{ Total } & \multicolumn{2}{|c|}{ Universidade } & \multicolumn{2}{|c|}{ Centro Universitário } & \multicolumn{2}{|c|}{ Faculdade } & \multicolumn{2}{|c|}{ IF e Cefet } \\
\hline & & Pública & Privada & Pública & Privada & Pública & Privada & Pública & Privada \\
\hline 2009 & 2314 & 100 & 86 & 7 & 120 & 103 & 1863 & 35 & n.a. \\
\hline 2010 & 2378 & 101 & 89 & 7 & 119 & 133 & 1892 & 37 & n.a. \\
\hline 2011 & 2365 & 102 & 88 & 7 & 124 & 135 & 1869 & 40 & n.a. \\
\hline 2012 & 2416 & 108 & 85 & 10 & 129 & 146 & 1898 & 40 & n.a. \\
\hline 2013 & 2391 & 111 & 84 & 10 & 130 & 140 & 1876 & 40 & n.a. \\
\hline 2014 & 2368 & 111 & 84 & 11 & 136 & 136 & 1850 & 40 & n.a. \\
\hline 2015 & 2364 & 107 & 88 & 9 & 140 & 139 & 1841 & 40 & n.a. \\
\hline 2016 & 2407 & 108 & 89 & 10 & 156 & 138 & 1866 & 40 & n.a. \\
\hline 2017 & 2448 & 106 & 93 & 8 & 181 & 142 & 1878 & 40 & n.a. \\
\hline 2018 & 2537 & 107 & 92 & 13 & 217 & 139 & 1929 & 40 & n.a. \\
\hline 2019 & 2608 & 108 & 90 & 11 & 283 & 143 & 1933 & 40 & n.a. \\
\hline
\end{tabular}

Fonte: Ministério da Educação (MEC) e Instituto Nacional Educação e Pesquisa (INEP) 
Abaixo pode-se conferir na figura (Figura 1) Direito no Brasil entre os meses de abril e junho com a evolução do número de Faculdades de do ano de 2020:

Figura 1 - Faculdades de Direito no Brasil

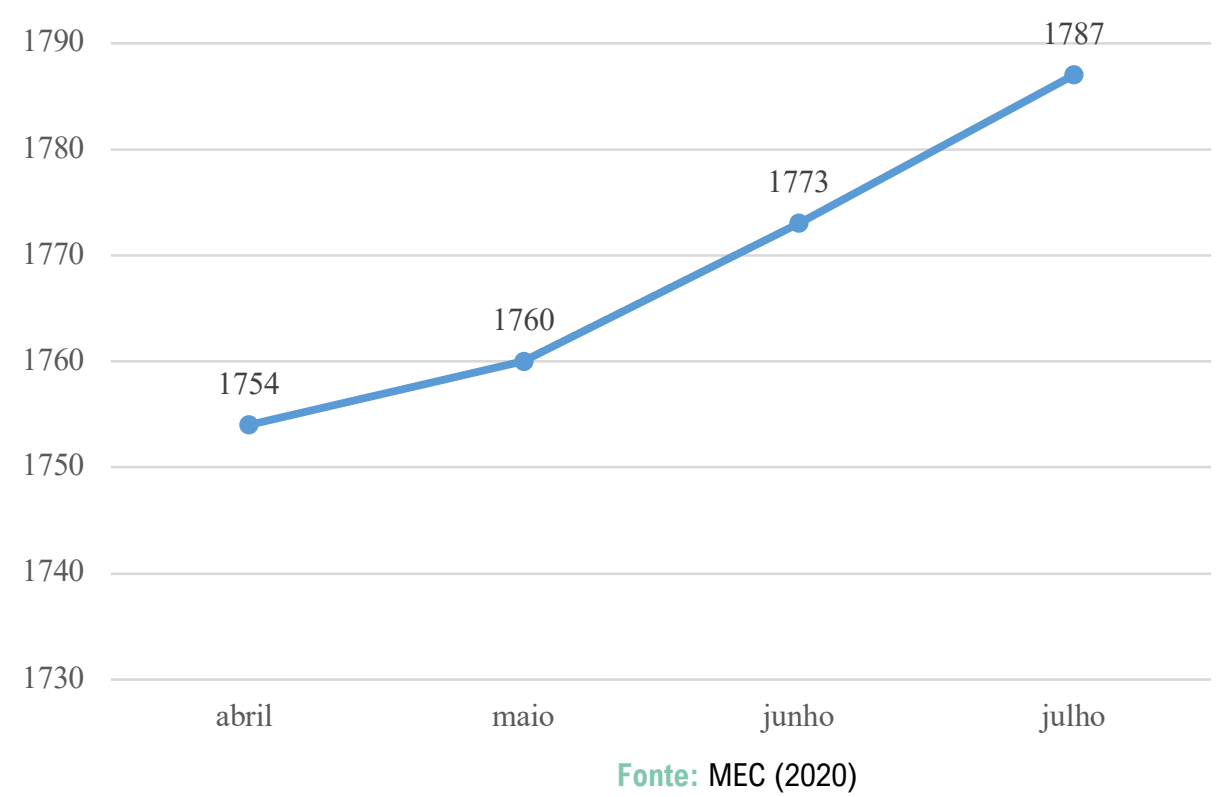

No mês de julho apresentou um acréscimo de 14 faculdades ativas, totalizando 1787 faculdades de Direito em todo território brasileiro.

De posse desses dados, depreende-se 0 número de profissionais do direito necessários para fazer essas 1787 faculdades de direito funcionarem em sua plenitude, sem mencionar aqui quantidade cursos jurídicos $\mathrm{e}$ especializações, pois essa informação é imprecisa. De referir que se trata de um mercado em plena expansão, sem previsão de retração, como fica demonstrado pelo gráfico, em que em plena pandemia, existe espaço para a expansão do mercado jurídico brasileiro.

No tocante ao número de cursos de direito em 2017 existiam 1203 cursos, existindo um forte aumento desde 1995 (Freitas, 2020), o qual é consentâneo com 0 crescimento das IES (Figura 2).

Figura 2 - Evolução do número de cursos de direito no brasil

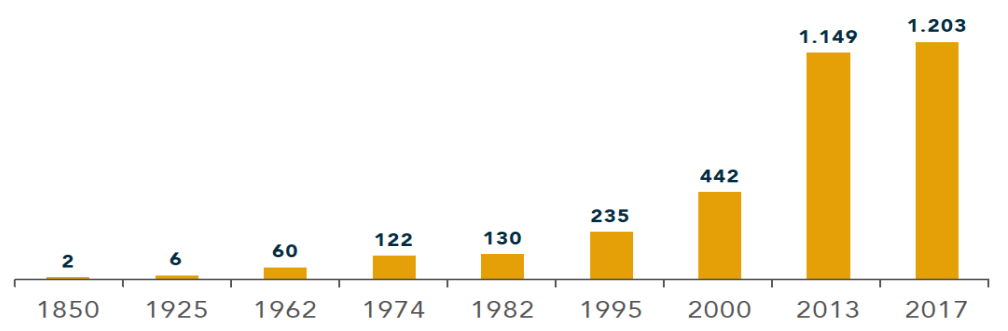


De acordo com Tenente (2017), este número torna-se ainda mais alarmante quando se verifica que outros grandes países como EUA, China e toda a Europa, juntos somam 1.100 cursos.

De acordo com o MEC, o curso de direito é a maior graduação do brasil Brasil (Ministério da Educação, 2020).

Essa expansão, pode sugerir um saturamento do mercado, para tanto, passaremos a analisar a quantidade de advogados que essas faculdades são capazes de formar e aprovar no exame da Ordem.

No Brasil a $O A B$, desde 2001, reconhece e premeia as IES atribuindo 0 "Selo $O A B$ RECOMENDA", a quem tenha critérios de excelência, regularidade e qualidade compatíveis com as exigências da $O A B$. Este selo é quase uma forma de avaliação das IES. De acordo com Fundação Getúlio Vargas (2020) em 2018, num total de 1502 cursos foram atribuídos apenas 161 selos.

\section{O Ensino do Direito em Portugal}

0 sistema de ensino superior em Portugal é um sistema binário que integra universidades e institutos politécnicos podendo as mesmas serem de cariz publico ou privado, e dentro desta de cariz universitário ou politécnico.

Em Portugal existem, atualmente 328 Instituições de Ensino Superior (IES), sendo
219 pertencentes ao Ensino Superior Público, das quais 117 são ensino politécnico e 95 ensino universitário, e 109 pertencentes ao Ensino Superior Privado, sendo 65 de cariz politécnico e 44 de cariz universitário e 7 pertencentes ao ensino superior militar e policial (DGEEC, 2020).

Com a implementação do Processo de Bolonha, são três os graus académicos de ensino superior oferecidos pelas IES em Portugal: licenciatura ( $1^{\circ}$ Ciclo), mestrado $\left(2^{\circ}\right.$ Ciclo) e doutoramento ( $\left.3^{\circ} \mathrm{Ciclo}\right)$.

As licenciaturaa em Direito, em virtude da Declaração de Bolonha, foram reduzidas de 5 para 4 anos letivos.

0 ensino superior caracteriza-se pela existência de números clausus definidos para cada IES e por curso.

Todos os cursos superiores são acreditados previamente pela A3ES - Agência de Avaliação e Acreditação do Ensino Superior, entidade instituída pelo Estado através do Decreto-lei no $369 / 2007$, de 5 de novembro, a quem incumbe também a acreditação da IES (Agência de Avaliação e Acreditação do Ensino Superior, 2020).

Existem 17 IES em Portugal que ministram curso de Direito, seja licenciatura, mestrado ou doutoramento), as quais se podem apresentar graficamente (Figura 3 e 4): 
Figura 3 - Universidade que ministram Licenciatura em Direito

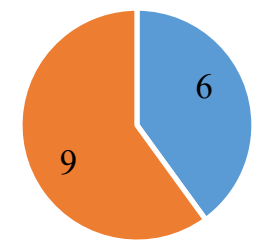

- U. Públicas —U. Privadas

Fonte: Inforcursos (2020)

9

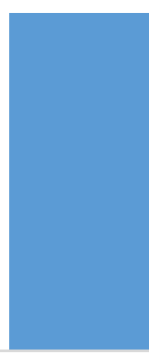

U. Públicas

Figura 4 - Universidade que ministram $2^{\circ}$ ciclo em Direito

Fonte: Inforcursos (2020)

Conforme se pode verificar e no tocante ao No tocante aos números de Cursos em si, número de IES que ministram $1^{0}$ ciclo podemos verificar a existência de 58 cursos de predomina o ensino privado, mas ao nível do $2^{\circ}$ direito de $1^{\circ}$ e $2^{\circ}$ ciclo, sendo 17 cursos de Ciclo predomina o ensino público. licenciatura e 41 de mestrado (Figura 5 e 6).

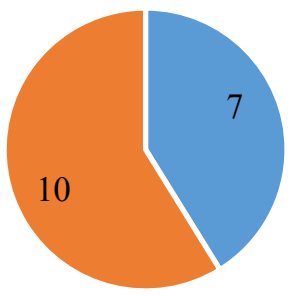

—U. Públicas —U. Privadas

Figura 5 - Número de Cursos em Direito - $1^{\circ}$ Ciclo - Licenciatura

Fonte: Inforcursos (2020) 
Figura 6 - Número de Cursos em Direito - $2^{\circ}$ Ciclo - Mestrado

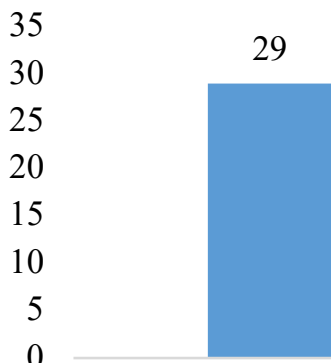

U. Públicas
12

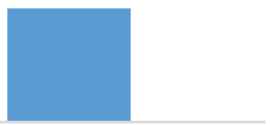

U. Privadas

Fonte: Inforcursos (2020)

Ao nível do número de cursos de direito, universidades publicas, as quais representam verificamos que quer sejam licenciatura quer $62 \%$ dos cursos (Figura 7 ):

mestrados, predomina 0 ensino nas

Figura 7 - Total de Cursos em Direito - $1^{\circ}$ e $2^{\circ}$ Ciclo

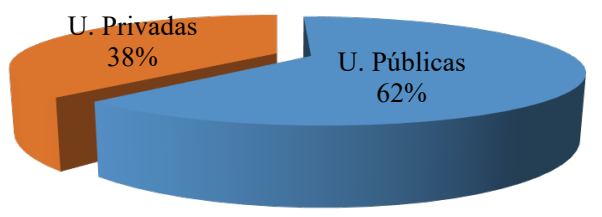

Fonte: Inforcursos (2020)

Importa salientar que em Portugal as áreas de candidatos mais diplomados do ensino educação e formação das ciências sociais, superior, seguidas da Engenharias (Figura 8): comércio e direito são as áreas com mais 


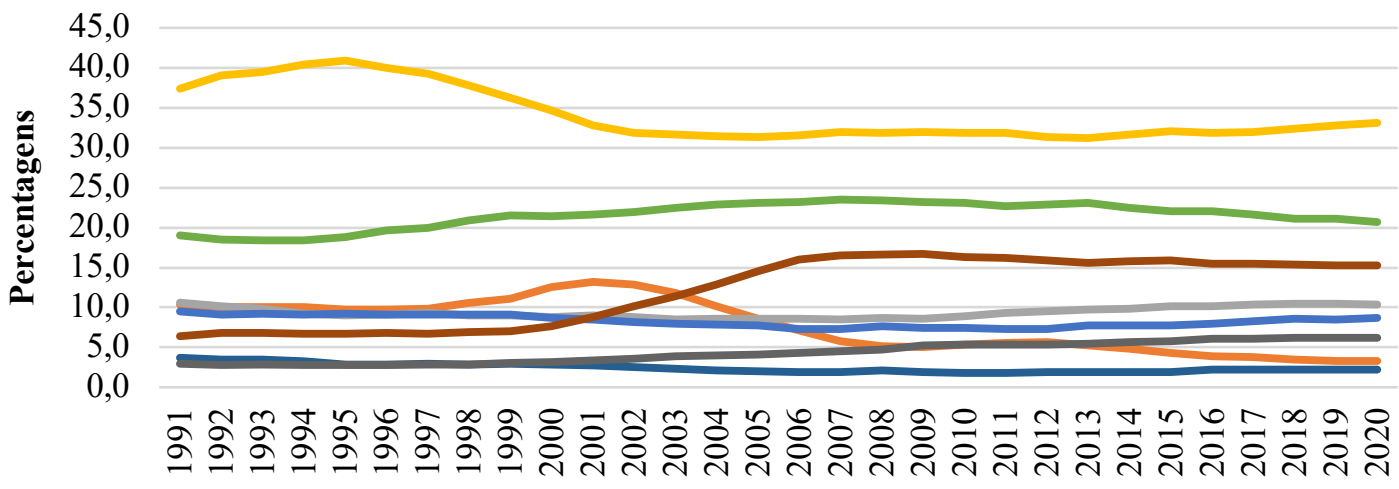

Anos

_ Áreas de educação e formação Educação

_ Áreas de educação e formação Artes e Humanidades

_-Áreas de educação e formação Ciências Sociais, Comércio e Direito

—_́reas de educação e formação Ciências, Matemática e Informática

— Áreas de educação e formação Engenharia, Indústrias Transformadoras e Construção

—Áreas de educação e formação Agricultura

— Áreas de educação e formação Saúde e Protecção Social

—Áreas de educação e formação Serviços

Figura 8 - Áreas de Educação e Formação dos Alunos do Ensino Superior

Fontes: DGEEC /ME-MCTES - DIMAS/RAIDES （2020); PORDATA (2020)

Em 2020 existiam 2761 vagas para o regime geral de acesso ao ensino superior para a licenciatura em Direito, na totalidade das IES, aos quais acrescem os regimes especiais de acesso, e, desde o ano 2.009, há sempre mais de 2.000 candidatos, por ano, em média, a iniciar o estágio de advocacia na Ordem dos Advogados:

Tabela 3 - Número de estagiário inscritos na ordem dos advogados

\begin{tabular}{|c|c|c|c|c|c|c|}
\hline \multicolumn{3}{|c|}{ № inscrições Ano } & \multicolumn{4}{|c|}{ Tipo de interveniente } \\
\hline & & $\underline{2019}$ & & 2018 & & 2017 \\
\hline Sexo & Advogados & \multicolumn{3}{|c|}{ Advogados Estagiário: Advogados } & \multicolumn{2}{|c|}{ Advogados E Advogados } \\
\hline Masculino & & 14933 & 1315 & 14617 & 1271 & 14195 \\
\hline Feminino & & 18365 & 2214 & 17751 & 2272 & 17131 \\
\hline Total & & 33298 & 3529 & 32368 & 3543 & 31326 \\
\hline
\end{tabular}

Fonte: Estatística da Justiça (2020)

Não obstante, podemos entender existir um numero de cursos de Direito, existem inúmeras profissões jurídicas (advocacia, magistratura judiciaria e do ministério público, solicitadoria e agentes de execução, notariado, Conservadores dos Registos) e para jurídicas (oficiais de justiça, polícia judiciária, polícia de segurança pública, guarda nacional 
republicana, polícia marítima, serviço de estrangeiros e fronteiras e ainda os mediadores e conciliadores em meios de resolução alternativa de litígios).

\section{Número de Advogados no Brasil}

Não é incomum encontrar advogados que acreditam existir muitos colegas de profissão exercendo a prática jurídica e o mercado estaria saturado.

Que existem mais advogados hoje, isso é claro e até pelo crescente número de faculdades de direito, esperado. Agora quanto a saturação do mercado de trabalho, entanto, nem sempre essa opinião é unânime e acaba se refletindo em uma nostalgia que é nada mais nada menos do que uma sensação de saudade idealizada, e às vezes irreal, por momentos vividos no passado associada a um desejo sentimental de regresso, impulsionado por lembranças que cada um possui.

Nesse prisma, como pudemos constatar pelos dados anteriores, o número de faculdades de direito aumentou exponencialmente, a profissão deixou de exalar o grau de exclusividade que detinha há décadas e deixou de ter o caráter elitista que carregava, sendo bem mais acessivel e democrática (ainda não como deveria ser) para grande parte dos brasileiros.

Se antes o advogado era uma figura quase intangível, de difícil acesso e que pela própria cultura acadêmica se mantinha distante da sociedade até pelo linguajar, em que 0 emprego do latim era mandatário e 0 vocabulário rebuscado fazia os mais humildes se distanciarem culturalmente, hoje a quantidade no mercado e a origem dos novos profissionais aproximou os novos profissionais das demandas sociais, tendo muitos origem humilde.

Então por lógico que os que viveram essa época elitista do direito, nutram um certo sentimento nostálgico, que como sabido a nostalgia não pode ser superada no campo físico pois diz respeito somente a uma visão idealizada de passado que cada um possui.

A próxima tabela (Tabela 4) apresenta 0 número de advogados ativos em todas as Seccionais do Brasil, com uma visão geral por Estado da Federação brasileira.

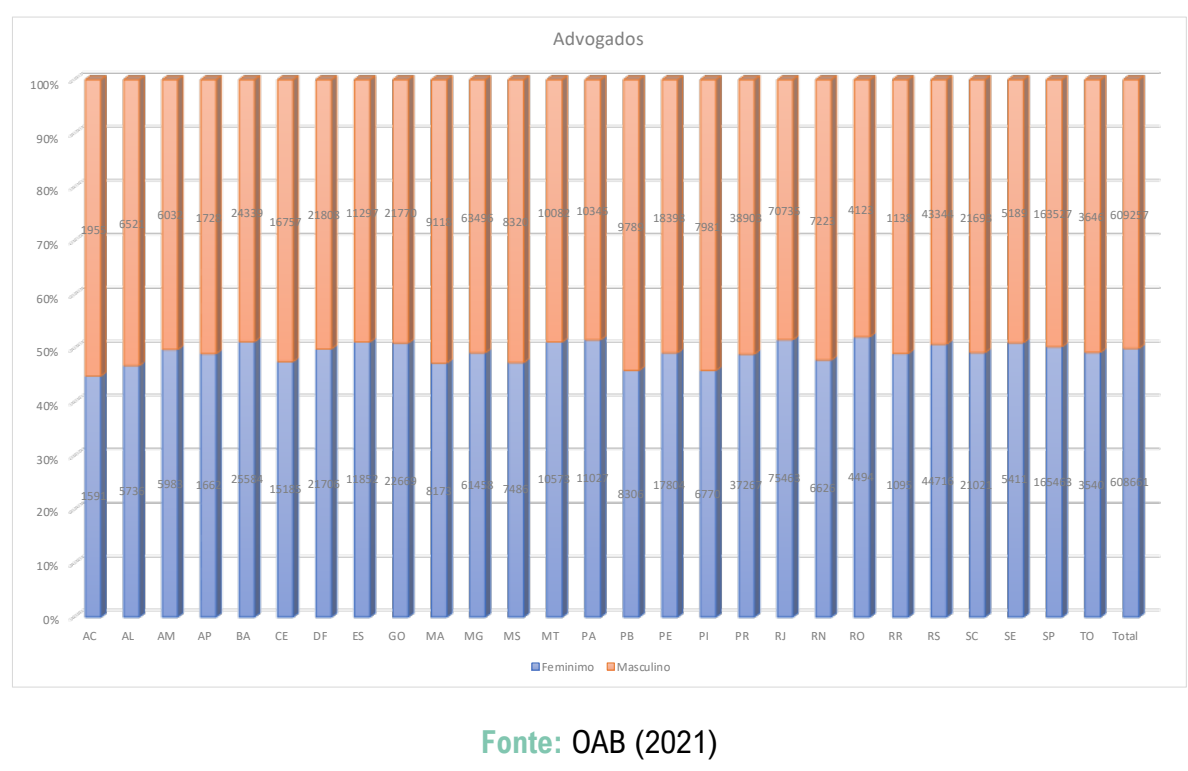


Atualmente, existem 1.217.918 advogados ativos, sendo 608.661 mulheres e 609.257 homens, demonstrando que a advocacia ainda é uma profissão predominantemente

masculina. Ao nível dos advogados estagiários existem 19360, sendo 10394 do sexo masculino e apenas 8966 do sexo feminino (Figura 9).

Figura 9 - Advogados em Portugal

\begin{tabular}{|c|c|c|}
\hline & vogados & Estagiários \\
\hline $\begin{array}{l}11000 \\
10500\end{array}$ & 10394 & \\
\hline 10000 & & \\
\hline 9500 & & 8966 \\
\hline 9000 & & \\
\hline 8500 & & \\
\hline 8000 & & \\
\hline & & 1 \\
\hline & feminino & \\
\hline
\end{tabular}

Fonte: OAB (2021)

Número de Advogados em Portugal

Atualmente em Portugal, de acordo com dados do Ministério da Justiça existem 33298 advogados (Figura 10).

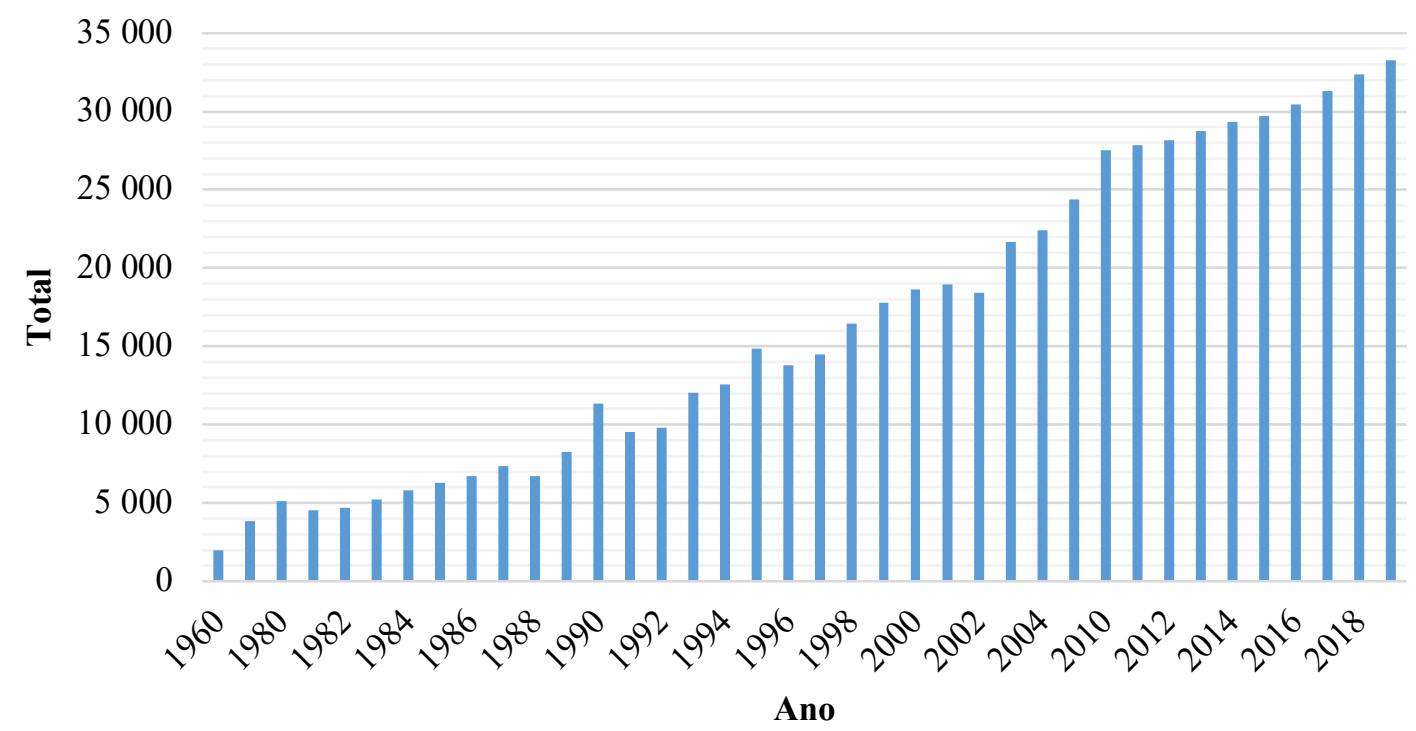

Fonte: DGPJ/MJ (2020); PORDATA (2020) 
Existe uma predominância feminina na Advogados e os homens 44,8\% (14933 profissão, representando as mulheres $55,2 \%$ advogados) (Figura 11). (18365 advogadas) dos inscritos na Ordem dos

Figura 11 - Advogados total e por género

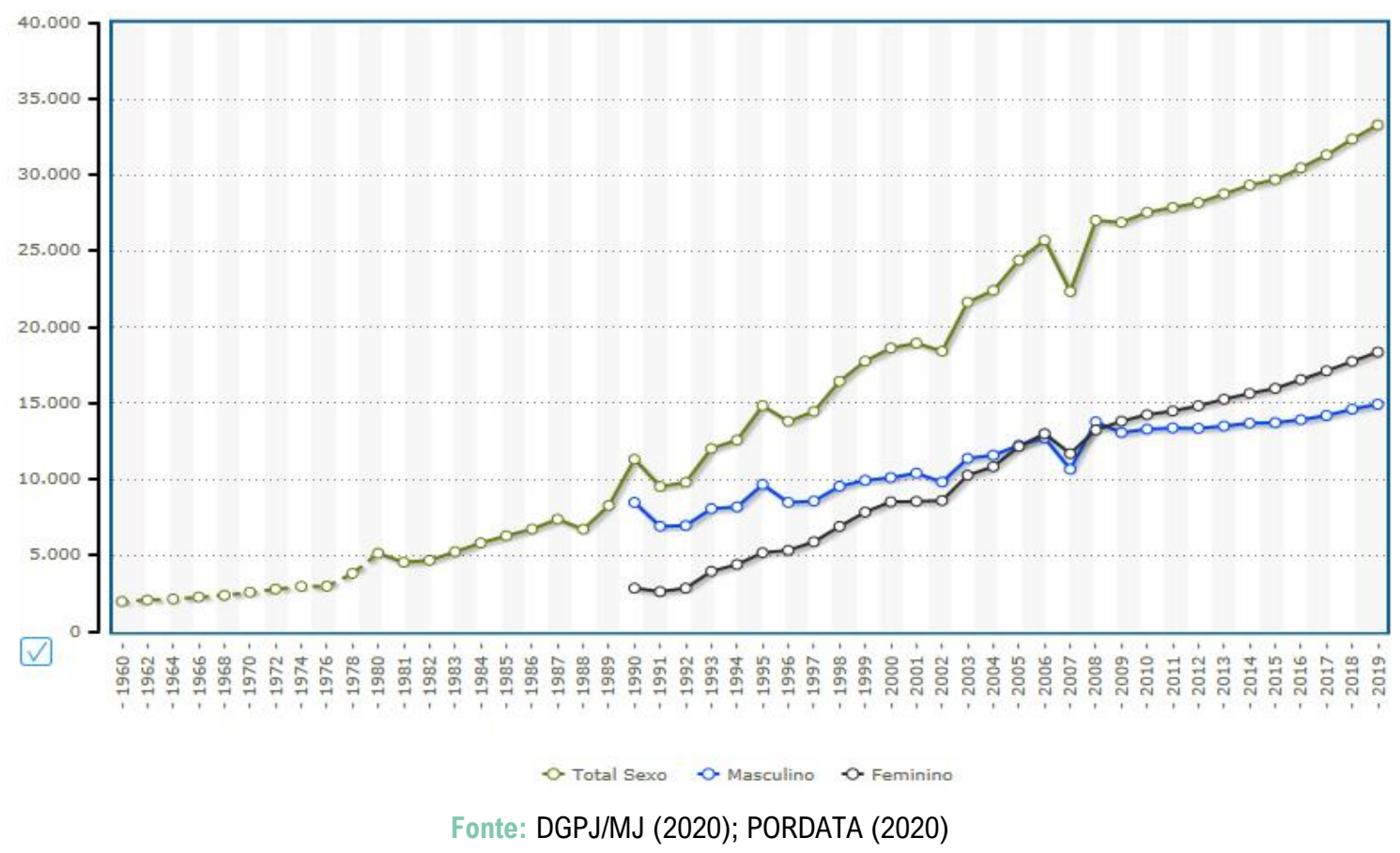

Pela análise dos dados (Figuras 10 e 11), podeCom base nos últimos dados (Tabela 4), fica se verificar que o número de advogados tem tido um crescimento irregular nos 20 anos, tendo estabilizado nos últimos 4 anos, em que o crescimento é de $3 \%$.

Conforme de Tabela 3, ao ano 2019 existiam 3529 advogados-estagiários (candidatos à advocacia), sendo 1315 homens e 2214 mulheres. demonstrado um desequilíbrio quanto ao número de advogados por estado em território brasileiro, sendo constatado elevada desproporcionalidade entre a quantidade dos estados membros da federação, havendo uma concentração desproporcional em apenas 10 estados.

Abaixo apresenta-se uma tabela com o número Distribuição Geográfica dos advogados por Estados Brasileiros de advogados demonstrando quais estados possuem a maior quantidade de Advogados ativos: 
Tabela 1 - Número de advogados por ordem decrescente por estado

\begin{tabular}{|c|c|c|c|c|}
\hline & Seccional & julho & Percentual & \\
\hline $\mathbf{1}^{\mathrm{o}}$ & SP & 325033 & $27,04 \%$ & \multirow{10}{*}{$80,65 \%$} \\
\hline $2^{\circ}$ & RJ & 145038 & $12,07 \%$ & \\
\hline $3^{0}$ & MG & 123345 & $10,26 \%$ & \\
\hline $4^{\circ}$ & RS & 87668 & $7,29 \%$ & \\
\hline $5^{\circ}$ & PR & 74986 & $6,24 \%$ & \\
\hline $6^{0}$ & BA & 49369 & $4,11 \%$ & \\
\hline $7^{\circ}$ & GO & 43759 & $3,64 \%$ & \\
\hline $8^{\circ}$ & DF & 42949 & $3,57 \%$ & \\
\hline $9^{\circ}$ & $\mathrm{SC}$ & 41859 & $3,48 \%$ & \\
\hline \multirow[t]{19}{*}{$10^{\circ}$} & PE & 35391 & $2,94 \%$ & \\
\hline & $\mathrm{CE}$ & 31126 & $2,59 \%$ & \\
\hline & ES & 22682 & $1,89 \%$ & \\
\hline & PA & 20953 & $1,74 \%$ & \\
\hline & MT & 20399 & $1,70 \%$ & \\
\hline & PB & 17958 & $1,49 \%$ & \\
\hline & MA & 16837 & $1,40 \%$ & \\
\hline & MS & 15638 & $1,30 \%$ & \\
\hline & PI & 14509 & $1,21 \%$ & \\
\hline & $\mathrm{RN}$ & 13666 & $1,14 \%$ & \\
\hline & $\mathrm{AL}$ & 12033 & $1,00 \%$ & \\
\hline & $\mathrm{AM}$ & 11885 & $0,99 \%$ & \\
\hline & SE & 10297 & $0,86 \%$ & \\
\hline & RO & 8498 & $0,71 \%$ & \\
\hline & TO & 7075 & $0,59 \%$ & \\
\hline & $\mathrm{AC}$ & 3544 & $0,29 \%$ & \\
\hline & AP & 3313 & $0,28 \%$ & \\
\hline & $\mathrm{RR}$ & 2219 & $0,18 \%$ & \\
\hline & Total & 1202029 & & \\
\hline
\end{tabular}

Além de uma desproporcionalidade na distribuição dos profissionais de direito em território nacional, deve-se colocar esse número sob o prisma do tamanho da população brasileira, pois por mais que o número de advogados possa soar elevado, é necessário levar em consideração como fica esse número em proporção a quantidade de habitantes.

\section{Distribuição Geográfica de Advogados em}

\section{Portugal}

A ordem dos Advogados Portugueses tem 7 conselhos Regionais: Lisboa, Madeira, Açores, Coimbra, Porto, Évora e Faro, distribuindo-se os advogados e advogados estagiários por estes conselhos. Contudo, não foi possível obter informação sectorial sobre essas inscrições.

Não existem dados estatísticos por distribuição geográfica.

\section{Advogados por População no Brasil}


De acordo com Instituto Brasileiro de Geografia e Estatística (IBGE), a população brasileira Porém, essa análise fica ainda mais possui 211803623 habitantes, dentre os quais, como pudemos verificar pelos dados trazidos anteriormente, 1202009 são advogados, portanto são quase $6 \quad(5,6)$ advogados para cada 1000 habitantes.

interessante quando realizado 0 desmembramento por estado.

Abaixo pode-se conferir uma tabela (Tabela 5) contendo o número de Advogados e a População:

Tabela 2 - número de Advogados e a População

\begin{tabular}{|c|c|c|}
\hline Seccional & Advogados & População \\
\hline $\mathrm{AC}$ & 3544 & 895943 \\
\hline $\mathbf{A L}$ & 12033 & 3356126 \\
\hline $\mathbf{A M}$ & 11885 & 4214337 \\
\hline AP & 3313 & 863351 \\
\hline $\mathbf{B A}$ & 49369 & 14935331 \\
\hline CE & 31126 & 9192733 \\
\hline DF & 42949 & 3056431 \\
\hline ES & 22682 & 4068287 \\
\hline GO & 43759 & 7125011 \\
\hline MA & 16837 & 7118810 \\
\hline MG & 123345 & 21304354 \\
\hline MS & 15638 & 2812133 \\
\hline MT & 20399 & 3529604 \\
\hline PA & 20953 & 8700884 \\
\hline PB & 17958 & 4040352 \\
\hline PE & 35391 & 9623726 \\
\hline PI & 14509 & 3281412 \\
\hline PR & 74986 & 11523849 \\
\hline RJ & 145038 & 17373026 \\
\hline $\mathbf{R N}$ & 13666 & 3537468 \\
\hline RO & 8498 & 1798225 \\
\hline $\mathbf{R R}$ & 2219 & 622500 \\
\hline RS & 87668 & 11426393 \\
\hline SC & 41859 & 7260191 \\
\hline SE & 10297 & 2321104 \\
\hline SP & 325033 & 46232860 \\
\hline TO & 7075 & 1592182 \\
\hline Total & 1202029 & 211806623 \\
\hline
\end{tabular}

Fonte: Instituto Brasileiro de Geografia e Estatística (2020)

Ao analisar do número de advogados para cada 1.000 habitantes temos o seguinte resultado (Tabela 6): 
Tabela 3 - Número de advogados por 1000 habitantes

\begin{tabular}{ll}
\hline Estado & Advogados/1000 \\
\hline DF & 14 \\
\hline RJ & 8 \\
\hline RS & 8 \\
\hline SP & 7 \\
\hline PR & 7 \\
\hline GO & 6 \\
\hline MG & 6 \\
\hline MT & 6 \\
\hline SC & 6 \\
\hline ES & 6 \\
\hline MS & 6 \\
\hline RO & 5 \\
\hline PB & 4 \\
\hline TO & 4 \\
\hline SE & 4 \\
\hline PI & 4 \\
\hline AC & 4 \\
\hline RN & 4 \\
\hline AP & 4 \\
\hline PE & 4 \\
\hline AL & 3 \\
\hline RR & 4 \\
\hline CE & 4 \\
\hline BA & 4 \\
\hline AM & 3 \\
\hline PA & 3 \\
\hline MA & \\
\hline
\end{tabular}

Fonte: Instituto Brasileiro de Geografia e Estatística (2020)

Assim diante dos dados, pode-se constatar que o Distrito Federal se destaca bastante dos estados da federação, possuindo uma média de 14 advogados para cada 1.000 habitantes, sendo São Paulo e Rio de Janeiro os segundos colocados com aproximadamente 8 advogados para cada 1.000 habitantes, enquanto tem estados da federação que contemplam números de 2 advogados para cada 1.000 habitantes, como o caso de Manaus e o Pará (Tabela 6).

\section{Advogados por População em Portugal}

A população Portuguesa atual é de 10.286,30 milhares segundo dados do Instituto Nacional de Estatística, dos quais 52,8\% são mulheres e $47,2 \%$ são homens.

Atualmente por cada 100.000 habitantes existem 323,4 advogados, percentagem que tem vindo a crescer desde 2009 ou seja 3,2 por cada 1000 habitantes (Figura 12). 


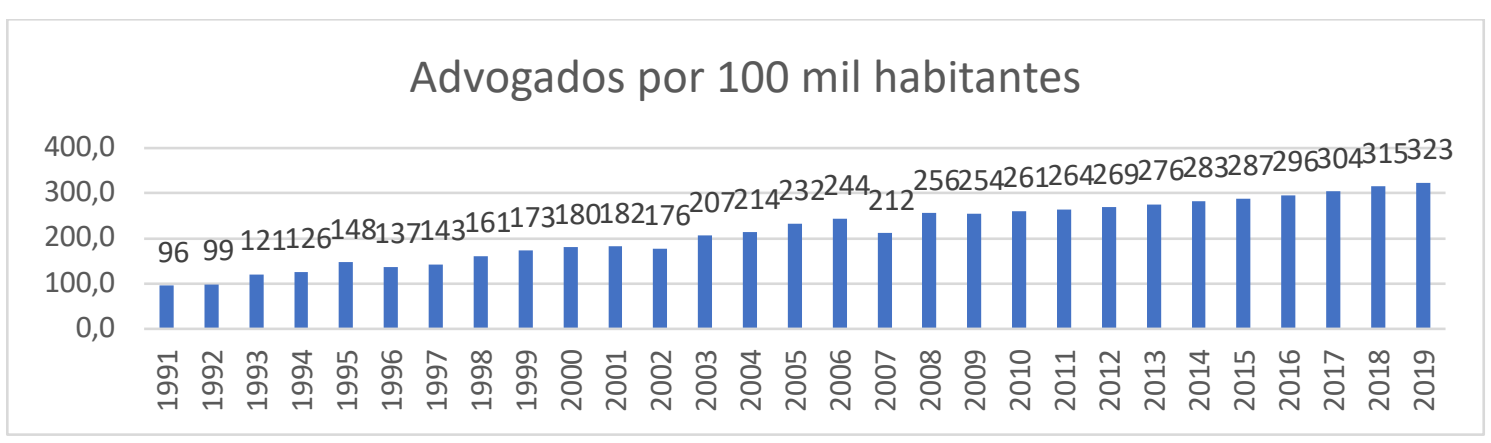

Fonte: DGPJ/MJ (2020); PORDATA (2020)

Pela análise dos dados (Figura12), pode-se Do gráfico infra podemos verificar igualmente verificar que o número de advogados tem as profissões jurídicas juntos dos tribunais, ou crescido nos últimos 4 anos a 3\%, enquanto a seja, juízes, magistrados de ministério publico população tem vindo a diminuir desde 2011 a e advogados por cada 100 mil habitantes 2018, exceto no último ano que cresceu 0,02\%. (Figura 13).

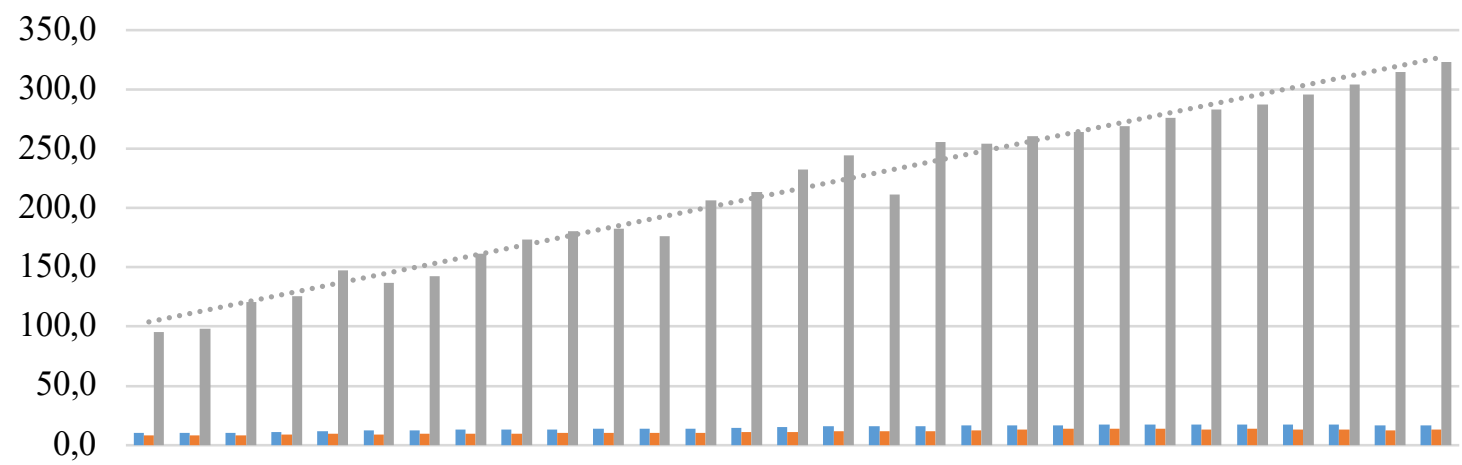

Magistrados judiciais por 100 mil hab. Magistrados do MP por 100 mil hab. Advogados por 100 mil hab. Linear (Advogados por 100 mil hab.)

Figura 1 - Advogados, Juízes e Magistrados do Ministério Publico por 100 mil Habitantes

Fonte: DGPJ/MJ (2020); PORDATA (2020)

Desde 2008 que o número de advogados por sendo atualmente $19(19,2)$ advogados por magistrado judicial também tem vindo a cresce, magistrado (Figura 14). 


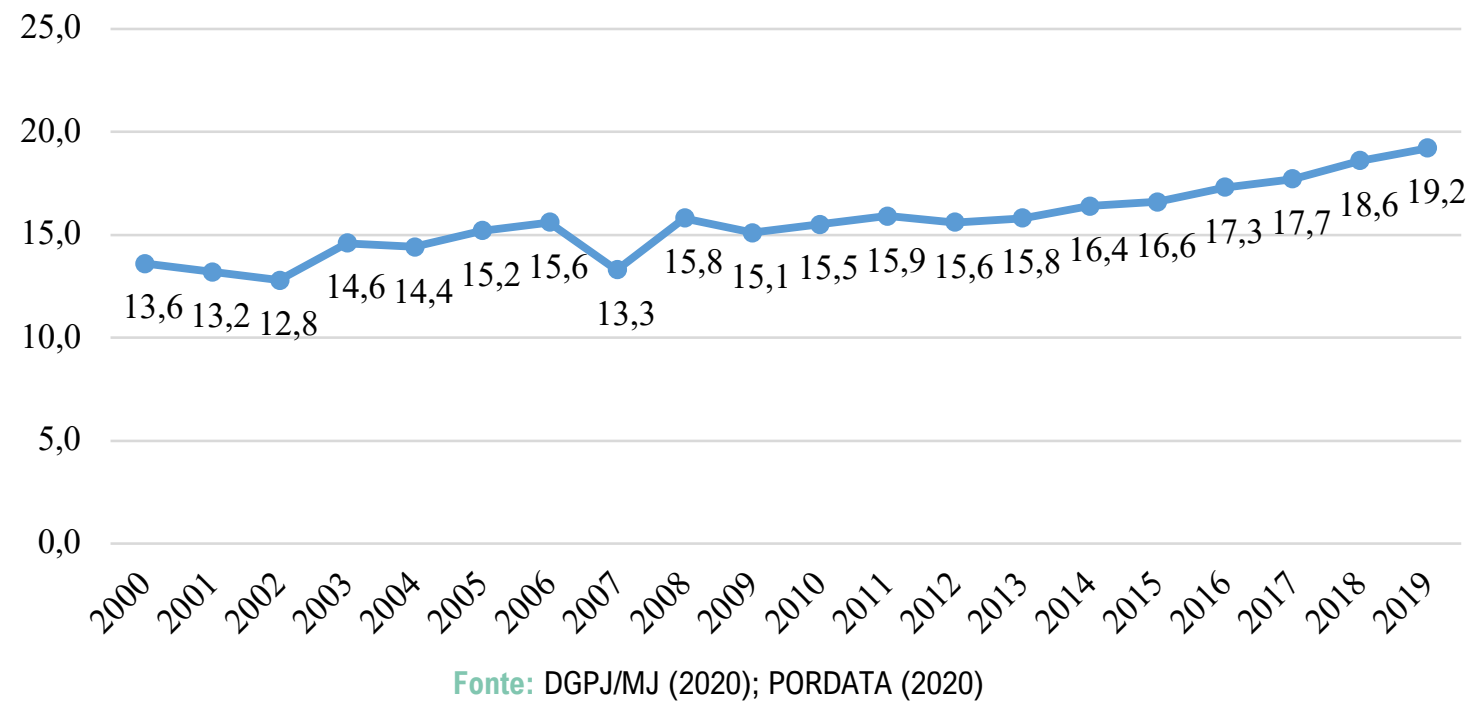

Advogados e os Processos pendentes no Brasil

No seu último balanço, o Poder Judiciário brasileiro finalizou o ano de 2019 com 77,1 milhões de processos em tramitação, que aguardavam alguma solução definitiva. Tal número representa uma redução no estoque processual, em relação a 2018, de aproximadamente 1,5 milhão de processos em trâmite, sendo a maior queda de toda a série histórica contabilizada pelo Conselho Nacional de Justiça, com início a partir de 2009.

Com estes números e tomando como base a quantidade de advogados inscritos nos quadros da Ordem dos Advogados do Brasil, se levarmos em consideração que todos estão atuando contenciosamente, chegamos a uma conclusão de que existem uma média de quase 65 (64.25) de processos ativos por advogado inscritos na Ordem, não sendo aqui possível auferir a quantidade de questões extrajudiciais e de consultoria dos advogados inscritos, mas evidenciando de que existem uma demanda considerável.

\section{Advogados e Processo pendentes em Portugal}

Em 2019, o número de processos pendentes nos tribunais judiciais de primeira instância era de 756 714, o que significa um decréscimo de cerca de $11,1 \%$, face ao ano de 2018 . Nestas pendências estão excluídos os processos dos tribunais de execução de penas (Figura 15). 


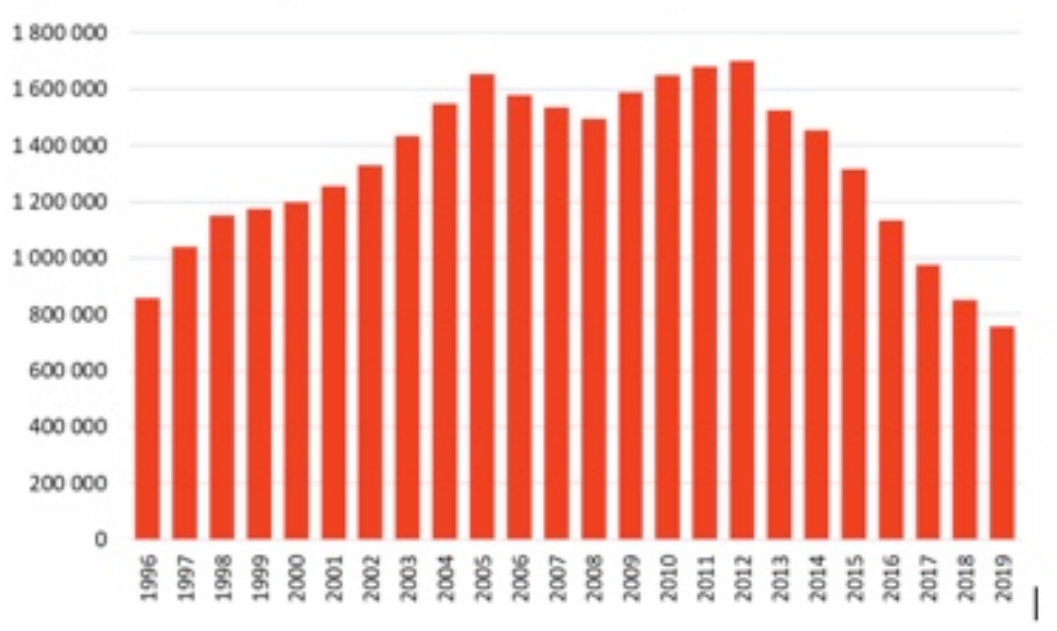

Fonte: DGPJ/MJ (2020)

Se consideramos que todos os advogados inscritos na Ordem dos Advogados pleitam em tribunal, temos uma média de $23(22,72)$ processos por advogados.
0 presente estudo procurou identificar e sistematizar os principais aspetos do mercado da advocacia no Brasil e Portugal, traduzindo o máximo de dados em números para facilitar a leitura e permitir destacar as principais diferenças e semelhanças entre os dois países no tocante às estatísticas. Nesta (sintética) comparação, pode-se concluir que, tanto Portugal, como o Brasil já dispõem de mecanismos legislativos e normativos que têm por objetivo regular o exercício da profissão de advogado, designadamente através da criação de uma Associação Publica para disciplinar a profissão - Ordem dos Advogados, que permitem gerar uma orgânica própria, criar regulamentação, estatutos e outros regulamentos. Neste campo, importa salientar que Portugal é mais regulador, na medida em tem uma legislação base que define os atos próprios dos advogados, criminalizando, inclusive, as condutas de terceiros que pratiquem tais atos sem a competente habilitação e inscrição na $0 A$. A vista disso, pode-se concluir que o Brasil e Portugal possuem aspetos semelhantes no tocante ao exercício da advocacia, nomeadamente pela obrigatoriedade de possuir um curso superior em direito e inscrição obrigatória na Ordem Profissional Representativa. De acordo com princípio da reciprocidade entre Portugal e Brasil, existe o livre acesso entre os países para o exercício da profissão, desde que ambos cumpram os respetivos requisitos dos seus cidadãos nacionais.

Observou-se, no Brasil, que apesar de numerosos casos fora do espectro absoluto dos dados, os advogados que, em sua essência são profissionais autónomos e empreendedores, não saem da faculdade diretamente para o mercado de trabalho com o devido conhecimento necessário para monetizar o seu trabalho. A atribuição do Selo 
$O A B$ tenta refletir esse reconhecimento aos cursos que cumpram as exigências da $O A$, em virtude da massificação dos cursos.

Em termos de dimensão existem diferenças substanciais. No mercado Brasileiro existem 6 advogados por cada 1000 Habitantes, quase 0 dobro de Portugal, o que pode demonstrar uma saturação do mercado brasileiro, com eventuais consequências para a classe, concretamente na baixa de qualidade, redução do preço dos honorários, entre outras.

Já em Portugal, apesar do número crescente de advogados inscritos na $O A$ em exercício efetivo da profissão, apesar de também não se pode descartar a saturação de mercado, no entanto, o número por 1000 habitante é reduzido, mas comparando outra grandeza, conclui-se que existem apenas cerca de 23 processos por advogado. Apesar de tudo, não se deve esquecer que a atividade da advocacia não se resume aos tribunais, mas a tantos outros procedimentos, contratos, resoluções extrajudiciais de conflitos, mais difíceis de identificar e quantificar. Acresce o facto de 0 número de advogados ter crescido em Portugal nos últimos 4 anos, $3 \%$ ao ano, enquanto que a população tem vindo a diminuir desde 2011 a 2018, exceto no último ano que cresceu $0,02 \%$, o que determina um crescimento real dos advogados superior, por decréscimo da população. Em Portugal existem apenas 17 IES a ministrar cursos de Direito, num universo de 328 IES, o que representa apenas $5,18 \%$ das IES. Existem, apenas, 17 cursos de licenciatura em Portugal, para cerca de 2761 vagas aos cursos, por ano, no regime geral de acesso ao ensino superior, pelo que atenua a situação de eventual saturação, dado que não significa um grande número de licenciados anualmente, atendendo à panóplia de profissões jurídicas existentes em Portugal. Por outro lado, no Brasil existem 2608 IES das quais 1787 ministram cursos de Direito, o que representa $68 \%$ das IES, razão pela qual a graduação em direito é a maior graduação do país. Em. Portugal, os cursos com maior frequências são as ciências sociais, o comércio e o direito, na sua globalidade.

Ainda no que concerne a diferenças no sistema de ensino, o modelo Português passa por um duplo crivo de fiscalização e controle, quer administrativo quer de qualidade: 0 ministério da Ciência e do Ensino Superior e da A3ES - Agência de Avaliação e Acreditação do Ensino Superior (Agência de Avaliação e Acreditação do Ensino Superior, 2020), garantindo a qualidade do mesmo. Por seu lado, no Brasil, não existe esta avaliação dos cursos nem das IES, e a avaliação de qualidade nos cursos de direito acaba por ser efetuada pela OAB através do Selo OAB RECONHECE.

Em Portugal a licenciatura em direito são 4 anos, a qual é seguida de um estágio obrigatório de 18 meses, supervisionado pela $\mathrm{OA}$, impondo, ainda, a figura do patrono advogado com mais de 5 anos de profissão, por forma a garantir a qualidade da formação do advogado. Neste âmbito, salientamos que 0 estágio não é curricular, não se encontra inserido no curso de direito. No Brasil, o grau de bacharel é de 5 anos, contemplando um estágio integrado, não existindo um estágio específico ministrado e supervisionado pela $\mathrm{OAB}$, pelo que se resume a um estágio curricular. Esta facto pode estar na origem da facilidade de acesso dos candidatos à profissão de advogado no Brasil. Com efeito, acedem à profissão após a frequência dos 5 anos do curso, sem necessidade de estágio específico de transição da vida académica para a prática jurídica, tanto de escritório como de barra. No caso de Portugal, o candidato tem de realizar um estágio de 18 meses, específico de advocacia, e efetuar um número mínimo de diligencias processuais, para, posteriormente, poder candidatar-se ao exame de admissão à OA. Em síntese, a formação de um advogado em Portugal é mais demorada do que no Brasil, 
prevendo a preparação teórica académica dada pela universidade e prática imposta pela ordem. É neste especto que reside a grande diferença no acesso à profissão, e que nos pode permitir concluir que os advogados portugueses têm a formação especifica de acesso à profissão, estruturada tendo em conta os desafios reais da profissão e as responsabilidades para com a comunidade.

\section{Limitações e Sugestões para trabalhos futuros}

Encontra-se como limitação a falta de quantos advogados brasileiros exercem em estatística sobre a relação direta entre o Portugal e vice-versa. número de licenciados em direito e os candidatos à advocacia (advogados estagiários), por forma a estabelecer que percentagem dos estudantes de direito envereda pela advocacia ou por outras profissões jurídicas.

Os dados estatísticos existentes em Portugal não são coincidentes com os dados estatísticos existentes no Brasil, ou seja, não foram conseguidos os mesmos dados estatísticos.

Foi também limitativo, 0 facto de não 0 presente estudo levanta questões sobre se ambos os países enfrentam os mesmos problemas, deixando como sugestões futuras de pesquisas o aprofundamento um estudo comparativo das condições de acesso à profissão, dos direitos e deveres dos advogados em cada um destes países, bem como das condições de exercício da profissão e ainda sobre as sociedades de advogados existentes em cada país e a sua forma de organização.

conseguirmos encontrar estatísticas que 

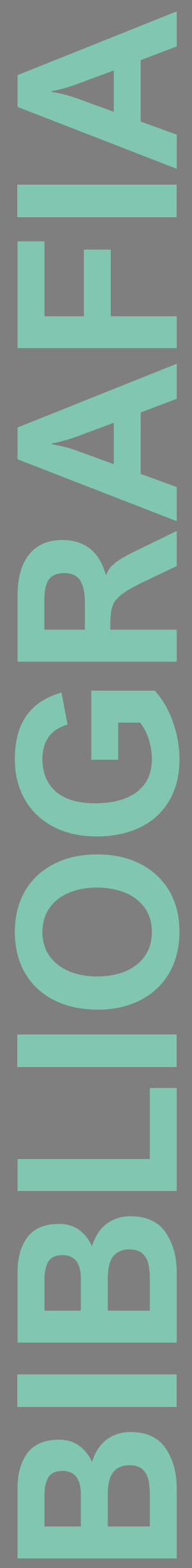

Agência de Avaliação e Acreditação do Ensino Superior. (2020). A3ES | A3ES. Retrieved March 25, 2021, from https://www.a3es.pt/

Collins, R. (1988). La Sociedad Credencialista. AKAL.

Couture, E., \& Silva, O. (1987). Os mandamentos do advogado (3rd ed.). Porto Alegre: Fabris Editor.

Decreto no 11:715 de 12 de junho de 1926, Pub. L. No. I Série, número 124 (1926). Retrieved from https://dre.pt/application/file/153795

Decreto-Lei n. ${ }^{\circ}$ 369/2007, de 5 de Novembro, Diário da República n. ${ }^{\circ}$ 212/2007, Série I de 2007-11-05. Retrieved from https://dre.pt/pesquisa/-/search/629433/details/maximized

DGEEC. (2021). Direção-Geral de Estatísticas da Educação e Ciência. Retrieved February 19, 2021, from http://www.dgeec.mec.pt/np4/73/

Direção-Geral da Política de Justiça. (2020, October 30). Advogados inscritos. Retrieved March 23, 2021, from https://estatisticas.justica.gov.pt/sites/siej/ptpt/Paginas/Advogados_inscritos.aspx

Estatísticas da Justiça. (2020). Estatísticas do Ministério da Justiça. Retrieved March 25, 2021, from https://estatisticas.justica.gov.pt/sites/siej/pt-pt

Freitas, H. (2020, April 14). Brasil tem mais de 1.500 cursos de Direito, mas só 232 têm desempenho satisfatório. Retrieved March 23, 2021, from https://www.jota.info/carreira/brasil-tem-mais-de-1-500-cursos-dedireito-mas-so-232-tem-desempenho-satisfatorio-14042020

Fundação Getulio Vargas. (2020). Exame de Ordem em números (Vol. IV). https://doi.org/10.1163/1568524041269322

Gil, A. (2017). Como Elaborar Projetos de pesquisa. (E. Atlas, Ed.) (6a edição). São Paulo.

Inforcursos. (2020). Dados e Estatísticas de Cursos Superiores. Retrieved March 25, 2021, from http://infocursos.mec.pt/

Instituto Nacional Educação e Pesquisa. (2020). Indicadores Educacionais . Retrieved March 25, 2021, from https://www.gov.br/inep/pt-br/acessoa-informacao/dados-abertos/indicadores-educacionais

Lei n.o 49/2004 de 24 de Agosto da Assembleia da República, Pub. L. No. Diário da República-I Série-A (2004). Retrieved from https://dre.pt/application/conteudo/479604

Lei no 145/2005 de 26 de janeiro da Assembleia da República, Pub. L. No. Diário da República - I Série-A (2005). Retrieved from https://dre.pt/application/conteudo/624462

Lei no 8.906 de 4 de julho de 1994 da Presidência da República, Pub. L. No. Casa Civil (1994). Retrieved from https://www.planalto.gov.br/ccivil_03/leis/18906.htm

Lei no 9.394 de 20 de dezembro de 1996 da Presidência da República, Pub. L. No. Casa Civil (1996). Retrieved from http://www.planalto.gov.br/ccivil_03/leis/19394.htm 
